\title{
Comparison of short-term energy intake and appetite responses to active and seated video gaming, in 8-11-year-old boys
}

\author{
Susan Allsop ${ }^{1 *}$, Benjamin P. Green ${ }^{1}$, Caroline J. Dodd-Reynolds ${ }^{2}$, Gillian Barry ${ }^{1}$ and Penny L. S. Rumbold ${ }^{1}$ \\ ${ }^{1}$ Department of Sport, Exercise and Rehabilitation, Faculty of Health and Life Sciences, Northumbria University, \\ Northumberland Building, Newcastle upon Tyne NE1 8ST, UK \\ ${ }^{2}$ School of Applied Social Sciences, Durham University, Durham DH1 3HN, UK \\ (Submitted 28 August 2015 - Final revision received 11 December 2015 - Accepted 15 December 2015 - First published online 28 January 2016)
}

\section{Abstract}

The acute effects of active and seated video gaming on energy intake (EI), blood glucose, plasma glucagon-like peptide-1 (GLP-1 ${ }_{7-36}$ ) and subjective appetite (hunger, prospective food consumption and fullness) were examined in 8-11-year-old boys. In a randomised, crossover manner, twenty-two boys completed one 90-min active and one 90-min seated video gaming trial during which food and drinks were provided ad libitum. EI, plasma GLP-1 ${ }_{7-36}$, blood glucose and subjective appetite were measured during and following both trials. Time-averaged AUC blood glucose was increased $(P=0.037)$; however, EI was lower during active video gaming (1.63 (SEM 0.26) MJ) compared with seated video gaming $(2.65$ (SEM 0.32$) \mathrm{MJ})(P=0 \cdot 000)$. In a post-gaming test meal $1 \mathrm{~h}$ later, there were no significant differences in EI between the active and seated gaming trials. Although estimated energy expenditure was significantly higher during active video gaming, there was still no compensation for the lower EI. At cessation of the trials, relative EI (REI) was significantly lower following active video gaming (2.06 (SEM 0.30) MJ) $v$. seated video gaming (3.34 (SEM 0.35) MJ) $(P=0.000)$. No significant differences were detected in time-averaged AUC GLP-1 ${ }_{7-36}$ or subjective appetite. At cessation of the active video gaming trial, EI and REI were significantly less than for seated video gaming. In spite of this, the REI established for active video gaming was a considerable amount when considering the total daily estimated average requirement for $8-11$-year-old boys in the UK (7.70 MJ).

Key words: Video gaming: Energy intake: Appetite: Satiety: Children

In England, one-sixth of children aged between 2 and 10 years are estimated to be obese ${ }^{(1)}$. Peak incidence of obesity appears to be during mid-to-late childhood, when aged between 7 and 11 years, particularly in boys ${ }^{(2)}$. Physical activity (PA) in childhood is key, as it lowers the risk of obesity and the related chronic and life-limiting conditions such as CVD and type 2 diabetes $^{(3)}$. The most recent data for England indicates that only $18.5 \%$ of children are achieving at least $60 \mathrm{~min}$ of moderate to vigorous PA per day ${ }^{(1)}$. Moreover, there is evidence of a decline in PA as children progress into adolescence ${ }^{(1,4)}$. One reason for this decline in PA could be a greater use of sedentary screenbased media ${ }^{(5)}$.

Active video gaming might provide a suitable replacement to seated-based video game play to potentially increase children's PA. Active video games integrate body movement (isolated limbs or whole body) into the game experience and video gaming. Movements are sensed via a hand-held motion controller (Nintendo $\mathrm{Wii}^{\mathrm{TM}}$ ), video cameras (Eye Toy ${ }^{\mathrm{TM}}$; Sony and Xbox Kinect $^{\mathrm{TM}}$; Microsoft) or weight-sensing platforms (Konami, Dance
Dance Revolution ${ }^{\mathrm{TM}}$ and Nintendo Wii $\left.\mathrm{Fit}^{\mathrm{TM}}\right)^{(6)}$. Recent active video gaming research with paediatric groups has established that game play produces greater energy expenditure (EE) and light to moderate PA when compared with resting, television viewing and seated video gaming ${ }^{(7-12)}$. There is also evidence that boys expend more energy than girls during active video game play ${ }^{(8,13)}$ and that they display greater enjoyment and engagement in this type of video game ${ }^{(13)}$. In view of the aforementioned findings, active video game play might be more of a feasible alternative to seated video gaming for boys, to increase PA levels.

In paediatric groups it appears that spontaneous energy intake (EI) both during and following sedentary screen-based media activity ${ }^{(14,15)}$ occurs, which exceeds the energy expended, and this could also occur during active video gaming. Recent active video gaming research has observed that EI can exceed EE following $1 \mathrm{~h}$ of game play in both 13-17-year-old boys ${ }^{(16)}$ and 12-15-year-old obese boys ${ }^{(17)}$. Furthermore, when the 13-17-year-old boys were monitored

Abbreviations: EE, energy expenditure; EI, energy intake; GLP-1 ${ }_{7-36}$, glucagon-like peptide-1; MET, metabolic equivalents; PA, physical activity; REI, relative EI; VAS, visual analogue scales.

* Corresponding author: S. Allsop, fax +44 191227 3190, email s.allsop@northumbria.ac.uk 
over $24 \mathrm{~h}$ after the trial, there was also a down-regulation in PA following active video gaming. Consequently, similar to matched seated video gaming and resting trials, the 13-17-yearold boys were found to be in a positive energy balance state following active video gaming ${ }^{(16)}$.

EI following active video game play ${ }^{(16,17)}$, however, might not be representative of children's real-life active video gaming practices, particularly as there is evidence of eating during play ${ }^{(11,19)}$. Recently, and in view of this, the EI from food and drinks offered ad libitum during both active and seated video gaming was explored, in 8-11-year-old boys ${ }^{(11)}$. The findings of the study established that $\mathrm{EE}$ was significantly greater from active video game play; however, EI during both trials was similar. As a result, the energy expended by active video game play did not counterbalance the EI during it ${ }^{(21)}$, yet, despite this, relative EI (REI) at cessation of gaming was significantly lowered. In the cited study, PA, EE and EI were not monitored beyond the gaming trials, and thus it is unknown whether any compensation occurred at a later time point. In addition, subjective appetite sensations (hunger, fullness and prospective food consumption), which were similar during both active and seated video gaming, provided no explanation for the similarity in $\mathrm{EI}^{(11)}$. EI both during and following active and seated video gaming should therefore be measured. In addition, appetite should be measured objectively, as well as subjectively, to explore whether homoeostatic-related signals can provide an explanation for the EI during both active and seated video game play. Only one seated video gaming study thus far has measured appetite signals related to hunger, alongside subjective appetite in $15-19$-year-old boys ${ }^{(14)}$. No differences were found in total ghrelin or serum insulin between trials during seated video gaming, yet blood glucose was significantly higher. According to the 'glucostatic theory' of short-term appetite regulation, a rise in glucose is indicative of a satiety response $^{(20)}$, yet the test meal EI of the 15-19-year-old boys following the 1-h seated gaming bout was greater, and post-gaming hunger sensations were not increased ${ }^{(14)}$. Satiety-related homoeostatic signals were not measured in this earlier study ${ }^{(14)}$, and thus it is unknown whether appetite signals related to satiety were raised. The measurement of satiety-related appetite might have provided an explanation for the increased EI following seated gaming or given an indication as to whether it may be because of hedonic mechanisms ${ }^{(14,21,22)}$.

Because of the lack of difference in hunger-related signals during seated video gaming in 15-19-year-old boys ${ }^{(14)}$ and the similarities in EI and appetite sensations of 8-11-year-old boys both during active and seated video gaming, it would be pertinent to measure satiety-related appetite signals. The measurement of satiety-related signals alongside subjective appetite could provide a more in-depth understanding of the mechanisms behind the spontaneous EI observed during both active and seated video gaming. The present study therefore aimed to assess acute EI, plasma glucagon-like peptide-1 (GLP-1 ${ }_{7-36}$ ), blood glucose and subjective appetite responses during and $1 \mathrm{~h}$ following 90-min bouts of active and seated video gaming, in 8-11year-old boys.

\section{Methods}

\section{Design}

A randomised, crossover design was used to compare plasma GLP-1 $1_{7-36}$, blood glucose, subjective appetite and EI responses of 8-11-year-old boys to active video gaming $v$. seated video gaming, each separated by 1 week. The active video gaming bouts used were representative of children's real-life active video gaming practices; that is, the type of active video game and console, the duration ( $\mathrm{min}$ ) and EI during gaming were identified in a previous study ${ }^{(18)}$. There were two gaming bouts: (1) $90 \mathrm{~min}$ of seated video gaming and (2) $90 \mathrm{~min}$ of active video gaming. During each gaming bout, food and drinks were offered ad libitum, enabling EI to be measured while gaming and also in a test meal $1 \mathrm{~h}$ later. The boys were placed into groups of two according to school year. Each group was then randomly assigned to a different bout every week so that by the end of the 2 weeks they had completed each trial.

The study was conducted according to 2013 Declaration of Helsinki ${ }^{\text {(23) }}$ and was approved by the University of Northumbria, Faculty of Health and Life Sciences Ethics Committee. Written informed consent was obtained from each child's parent and assent from every boy, before data collection.

\section{Participants}

To recruit 8-11-year-old boys, consent was obtained from the head teacher of a primary school located within the city of Newcastle upon Tyne (North East England, UK). Recruitment packs were distributed to all eligible boys who expressed an interest in participating, and they were asked to take it home to their parents. The pack contained a letter addressed to their parents with a full explanation of the study, and consent forms for them and their child (if able) to sign and return to school. Signed consent forms were received from twenty-two boys (mean age 9.9 (sem 0.2) years). Boys were excluded if they had intolerances or allergies to the foods provided in the study or had an injury or illness that prevented their play of active video games. Overall, twenty-two boys participated in the study.

\section{Preliminary measures}

Before the first gaming trial, the researchers met the children (and where applicable, their parent) at the school for familiarisation. The boys were familiarised with the gaming consoles (Nintendo $\mathrm{Wii}^{\mathrm{TM}}$ ), games (Nintendo Wii ${ }^{\mathrm{TM}}$ Sports tennis), the gaming session format, the self-reported weighed food diaries and visual analogue scales (VAS) that were used to explore subjective appetite sensations. The researchers demonstrated the right hip placement of accelerometers (Actigraph GT3X+; Actigraph LLC $^{(}$) used for the measurement of PA during the gaming trials. The boys were asked to complete a food preference questionnaire to ensure that they did not dislike the foods and drinks offered during the study. They completed the Dutch Eating Behaviour Questionnaire for children, as a measure of dietary restraint ${ }^{(24)}$. Stature and seated height were measured to the nearest $0.01 \mathrm{~m}$ using a Harpenden Portable Stadiometer (Holtain Limited). Body mass was measured to the 
nearest $0 \cdot 1 \mathrm{~kg}$ using portable SECA scales (SECA). Waist circumference was measured to the nearest $0.01 \mathrm{~m}$ with a nonelastic flexible tape at each boy's natural waist while standing, as an indication of central adiposity ${ }^{(25)}$.

\section{Protocol}

Each boy was provided with a self-report, weighed food diary and a set of food weighing scales (Salter ${ }^{\mathbb{Q}}$ ). With the help of their parent, they were asked to weigh and record all foods and drinks that they consumed from 17.00 hours the evening before until after they had consumed breakfast on the morning of each trial day. A photocopy of the food diary was provided to each parent who was asked to replicate their child's food and drink intake before the second gaming trial. With the help of school staff and parents, the boys abstained from all physical education at school on the day of the study and PA from 17.00 hours the preceding evening.

On the trial days, the boys were met at school at 08.30 hours by two members of the research team and escorted to the University laboratory. On arrival (approximately 08.50 hours), the boys rested until 09.00 hours when they completed baseline appetite VAS. Immediately following this $(t=0 \mathrm{~min})$, a fingerprick blood sample $(300 \mu \mathrm{l})$ was taken from each boy to enable the determination of baseline plasma GLP-1 ${ }_{7-36}$ and blood glucose.

The boys completed additional appetite VAS at $45 \mathrm{~min}$ during gaming, at the end of gaming $(90 \mathrm{~min}), 45 \mathrm{~min}$ post gaming (135 min) and immediately following the test meal (180 min). Further fingertip blood samples $(300 \mu \mathrm{l})$ were taken at $45 \mathrm{~min}$ during gaming, at the end of gaming $(90 \mathrm{~min}$ ) and $45 \mathrm{~min}$ post gaming $\left(135 \mathrm{~min}\right.$ ) for the determination of plasma GLP-1 ${ }_{7-36}$ and blood glucose. Upon termination of each 90-min gaming trial, the boys rested for $60 \mathrm{~min}$, following which they were provided with an ad libitum test meal, before being returned to school by the research team. A diagrammatic representation of the study protocol is provided in Fig. 1.

Gaming trials. The design of the individual gaming trials was based on published data, which described the active gaming practices of 7-11-year-old children from Newcastle upon Tyne $^{(18)}$. The active video gaming console used was Nintendo $\mathrm{Wii}^{\mathrm{TM}}$, and the game was Nintendo $\mathrm{Wii}^{\mathrm{TM}}$ Sports tennis ${ }^{(18)}$. The seated video game used was 'Mario and Sonic at the London 2012 Olympic Games', which was played on the handheld device, Nintendo $\left.{ }^{(}\right)$3DS. The two gaming trials took place on the same school day of each week over two consecutive weeks. The two gaming trials were as follows: (1) 90-min seated video gaming during which food and drinks were offered ad libitum; (2) 90-min active video gaming during which food and drink were offered ad libitum. The two aforementioned gaming bouts have been successfully used in previous gaming and appetite work with young boys ${ }^{(11)}$.

Energy intake. The food and drink items provided during the gaming sessions were based on previous findings ${ }^{(18)}$ and comprised $130 \mathrm{~g}$ of apples (raw, slices and cored), $50 \mathrm{~g}$ of crisps (potato chips (Walkers ${ }^{\odot}$, ready salted)), $250 \mathrm{ml}$ of semiskimmed milk and $250 \mathrm{ml}$ of 'Jucee' apple and blackcurrant squash (no added sugar). All food items were pre-weighed by the researchers to the nearest gram using electronic portable scales (Salter ${ }^{\circ}$ ), and all drinks were measured to the nearest millilitre. The crisps and apple were placed in clear plastic bags, and the milk and squash were placed in coloured drinks bottles so that volumes could not be detected. All items were numerically coded by the researchers and placed at a station designated to each individual boy, who was offered them ad libitum. When the gaming trials commenced, the time of the first eating episode for each boy was recorded. The researchers noted each bag or bottle taken by the boys, and anything left over was weighed or measured so that the amounts consumed could be calculated and recorded. Food and drink items were topped up before being finished, during the gaming bouts.

The ad libitum test meal provided after the gaming bouts was pasta, with tomato sauce, Cheddar cheese and olive oil (ASDA), which was served in excess and topped up before being finished. The boys were instructed to eat until they felt comfortably full, at which point the meal was terminated. As they ate the test meal, the bowl was refilled by the researchers. The research team covertly weighed the test meal before it was served and as the meal was terminated. The macronutrient content of the meal was $58 \%$ carbohydrate, $28 \%$ fat and $14 \%$ protein, and it provided $450 \mathrm{~kJ}(107.5 \mathrm{kcal}) / 100 \mathrm{~g}$ of total energy, similar to a pasta meal used in a previous adolescent appetite study ${ }^{(26)}$. EI for all of the food and drink items served was estimated from individual food labels, an online resource (www.asda.com) and Microdiet (Downlee Systems ${ }^{\circledR}$ ).

Physical activity assessment. During both gaming bouts, the PA levels of each boy were measured by accelerometry using an Actigraph GT3X+ (Actigraph LLC $^{\circ}$ ) placed on the right hip, as this is considered the optimum site for PA monitoring ${ }^{(27)}$. PA counts were recorded in $10 \mathrm{~s}$ epochs. After each trial, the accelerometer data were downloaded using Actilife version 6 data analysis software and interpreted using recommended child-appropriate activity cut-off values ${ }^{\text {(28) }}$. Activity counts were converted into mean metabolic equivalents (MET) using MET thresholds recommended for use with children: sedentary $<1.5 \mathrm{MET}$; light 1.5 to $<4$ MET; moderate 4 to $<6$ MET; vigorous $>6 \operatorname{MET}^{(29)}$.

Energy expenditure. For each boy, Henry's body mass, stature and sex-specific equations were used to calculate $\mathrm{BMR}^{(30)}$. EE was then calculated as recommended by Ridley et $a l^{(31)}$, as follows: $\mathrm{MET} \times \mathrm{BMR}(\mathrm{MJ} \times \mathrm{min} / \mathrm{d}) \times 90 \mathrm{~min}$ gaming $=\mathrm{MJ}$.

Relative energy intake. For each boy, EE was subtracted from the amount of energy consumed during each 90-min gaming bout and also from the test meal to calculate REI.

Subjective appetite. Hunger, fullness and prospective food consumption were assessed using VAS. Questions asked were as follows: 'How hungry do you feel now?' accompanied by the statements very hungry (0) and not at all hungry (100); 
'How full do you feel now?' accompanied by very full (0) and not full at all (100); and prospective food consumption 'How much would you like to eat now?' accompanied by a lot (0) and nothing at all (100). The boys were requested to place a vertical mark along the 100-mm horizontal lines. Scales were collected before the commencement of gaming (baseline $t=0 \mathrm{~min}$ ), at $45 \mathrm{~min}$ during gaming, at the end of gaming (90 min), $45 \mathrm{~min}$ post gaming $(135 \mathrm{~min})$ and immediately after the test meal (180 min).

Blood sampling. To obtain blood samples, the fingertip capillary blood sampling and handling method used by Green et $a l .{ }^{(32)}$ was followed. For the measurement of GLP-1 ${ }_{7-36}$, capillary blood samples were collected immediately before the gaming bouts commenced (baseline $t=0 \mathrm{~min}$ ), midway during the gaming bout ( $45 \mathrm{~min}$ ), at the end of the gaming bout (90 min) and at $45 \mathrm{~min}$ post gaming (135 min) (Fig. 1). The fingertip puncture site was cleaned with an aseptic wipe and then pierced with a sterile automated lancet (Accu Check). The blood was collected into a pre-cooled EDTA microvette pretreated with aprotinin $(33 \mu \mathrm{l} / \mathrm{ml})$ and dipeptidyl-dipeptidase IV inhibitor $(30 \mu \mathrm{l} / \mathrm{ml})$ to aid in the preservation of $\mathrm{GLP}-1_{7-36}$. Immediately following blood collection, the microvettes were placed on ice and spun at $1500 \boldsymbol{g}$ for $10 \mathrm{~min}$, enabling aliquots of the plasma supernatant to be pipetted into labelled Eppendorfs and stored at $-80^{\circ} \mathrm{C}$ for later quantification.

At the same time as blood was collected for the determination of GLP-1 $1_{7-36}$, a sample was also obtained from the same puncture site to establish blood glucose concentrations. Each of these blood samples $(0.02 \mathrm{ml})$ was drawn into a $\mathrm{Na}$ heparinised capillary tube and transferred into an Eppendorf containing $1 \mathrm{ml}$ of haemolysis solution (EKF Diagnostics). Samples were shaken to encourage haemolysis and then immediately placed on ice.

Blood analysis. GLP-1 $1_{7-36}$ was quantified by electrochemiluminescence, using a human hormone multiplex assay (Sector Imager 2400; Meso Scale Discovery). To reduce inter-assay variation, samples from each boy were analysed on the same assay plate. The CV was established as $5.5 \%$. The blood glucose samples were quantified by the glucose oxidase method using an automated glucose analyser (Biosen C line; EKF Diagnostics).

\section{Statistical analysis}

In all, twenty-one boys were included in the statistical analysis, as data for one of the boys were excluded due to his EI being different in the requested period of replication, prior to the first and second trials. One more boy was unable to provide blood samples during the trials, but all other data collected from him were included in the analysis. IBM ${ }^{\odot}$ SPSS (version 22.0; SPSS Inc.) was used for all analyses. Data were checked for normality using the using Shapiro-Wilk test, and means with their standard errors were calculated for all variables. Data from twenty boys were included for GLP-1 $1_{7-36}(\mathrm{pg} / \mathrm{ml})$ and blood glucose. To establish the effect of gaming, plasma GLP-1 $1_{7-36}(\mathrm{pg} / \mathrm{ml})$ and blood glucose $(\mathrm{mmol} / \mathrm{l})$ responses were calculated as timeaveraged AUC $\times 135 \mathrm{~min}$ for both gaming trials. To establish the effect of the trials on subjective hunger, prospective food consumption and fullness, VAS ratings $(\mathrm{mm})$ were calculated as time-averaged AUC $\times 180 \mathrm{~min}$. Time-averaged AUC values for plasma GLP-17-36, blood glucose and subjective appetite sensations, along with gaming and test meal EI, gaming macronutrient EI (carbohydrate, fat and protein), PA (MET), EE (MJ), REI (MJ), time to eating onset during gaming (min) and the ingestion time of the test meal (min) were analysed using paired $t$ tests. When significant differences occurred, Cohen's $d$ effect size was calculated and interpreted against the effect size categories of $\leq 0 \cdot 20=$ small effect, approximately $0 \cdot 50=$ moderate effect and $\geq 0 \cdot 80=$ large effect ${ }^{(33)}$. Significance was set at $P<0.05$ for all analyses. To aid in the interpretation of clinically meaningful statistical differences, time-averaged AUC values $\times$ $90 \mathrm{~min}$, determined from a between-variation study of fasted plasma GLP-1 $1_{7-36}(4 \cdot 8 \cdot 1$ (SEM $\left.0 \cdot 1) \mathrm{pg} / \mathrm{ml}\right)$ and blood glucose $(5 \cdot 1$ (SEM $0 \cdot 0) \mathrm{mmol} / \mathrm{l})$ in 8-11-year-old boys, were used (S. Allsop, C. J. Dodd-Reynolds, B. P. Green and P. L. S. Rumbold, unpublished results).

\section{Results}

\section{Population characteristics}

The twenty-one boys were of mean stature 1.45 (SEM 0.02) $\mathrm{m}$, body mass 37.9 (SEM 1.6) kg, with a mean waist circumference of $64.3($ SEM 1.7$) \mathrm{cm}$ and BMI of $18 \cdot 1$ (SEM $0 \cdot 7) \mathrm{kg} / \mathrm{m}^{2}$. According to 
Table 1. Serving size, total energy and macronutrient values of food and drink items served during the gaming bouts

\begin{tabular}{|c|c|c|c|c|c|}
\hline Foods or drinks & Serving size & Energy (MJ) & Carbohydrate (g) & Fat $(g)$ & Protein $(\mathrm{g})$ \\
\hline Apples ('Royal Gala' raw, sliced and cored) & $130 \mathrm{~g}$ & 0.26 & $15 \cdot 60$ & 0.13 & 0.52 \\
\hline Walker's $^{\circ}$ ready salted crisps & $50 \mathrm{~g}$ & $1 \cdot 10$ & 25.75 & 15.95 & 3.05 \\
\hline Semi-skimmed milk & $250 \mathrm{ml}$ & 0.52 & 12.00 & 4.50 & 9.00 \\
\hline 'Jucee' apple and blackcurrant squash (no added sugar) & $250 \mathrm{ml}$ (1:5 dilution) & 0.03 & 2.50 & 0.00 & 1.30 \\
\hline
\end{tabular}

Table 2. Gaming energy intake (EI) (MJ), time to eating onset during gaming (min) physical activity (PA) metabolic equivalents (MET), energy expenditure $(\mathrm{EE})(\mathrm{MJ})$, gaming relative $\mathrm{EI}(\mathrm{MJ})$, test meal $\mathrm{EI}(\mathrm{MJ})$, total relative $\mathrm{El}$ and ingestion time of test meal (min) for all boys $(n 21)$ for each gaming trial (Mean values with their standard errors)

\begin{tabular}{|c|c|c|c|c|c|}
\hline & \multicolumn{2}{|c|}{ Seated video gaming } & \multicolumn{2}{|c|}{ Active video gaming } & \multirow[b]{2}{*}{$P$} \\
\hline & Mean & SEM & Mean & SEM & \\
\hline Gaming EI (MJ) & $2 \cdot 65$ & 0.32 & 1.63 & 0.26 & $<0.001^{*}$ \\
\hline Time to eating onset during gaming ( $\mathrm{min}$ ) & 7.50 & $2 \cdot 32$ & $9 \cdot 11$ & $2 \cdot 41$ & 0.811 \\
\hline PA MET & 1.22 & 0.04 & 1.99 & 0.11 & $<0.001^{*}$ \\
\hline $\mathrm{EE}(\mathrm{MJ})$ & 0.39 & 0.01 & 0.64 & 0.03 & $<0.001^{*}$ \\
\hline Gaming relative El (MJ) & $2 \cdot 26$ & 0.32 & 0.99 & 0.26 & $<0.001^{*}$ \\
\hline Test meal El (MJ) & 1.08 & 0.12 & 1.07 & 0.10 & 0.859 \\
\hline Total relative EI (MJ) & 3.34 & 0.35 & 2.06 & 0.30 & $<0.001^{*}$ \\
\hline Ingestion time of test meal (min) & 11.02 & 4.53 & 8.48 & 3.33 & 0.051 \\
\hline
\end{tabular}

* Significant difference between the active and seated video gaming trials.

UK age and sex-specific BMI centiles ${ }^{(34)}$, the majority of the boys were classified as having a healthy body mass (77.3\%), $9 \cdot 1 \%$ were classified as overweight and $13.6 \%$ were classified as obese. Mean maturity offset was -0.3 (SEM 0.3 ) years, indicating that as a group the boys were 3.6 months from peak height velocity and of similar maturation status. All boys were identified as being unrestrained eaters with a mean dietary restraint score of $1 \cdot 8$ ( $\operatorname{sem} 0 \cdot 13)$, categorised as being average for boys of this age $(1.53(\text { SEM } 0.06))^{(24)}$.

\section{Physical activity and energy expenditure}

All values for PA (MET), EE and REI are displayed in Table 1. Active video gaming elicited light PA (MET) and EE, which was significantly greater than the sedentary levels produced by seated gaming (all $P=0 \cdot 000$, moderate effect size $d=0 \cdot 7$ ).

\section{Energy intake and relative energy intake}

Table 2 indicates that the boys consumed significantly more during seated video gaming compared with active video gaming (small effect, size $d=0 \cdot 3$ ). As a percentage of total EI $(\mathrm{MJ})$, the boys consumed significantly more carbohydrate (58.3 (sem 16.7)\%, $P=0.004$, small effect size $d=0.3$ ) and protein $(6 \cdot 8$ (SEM 4.4$) \%, P=0 \cdot 022$, small effect size $d=0 \cdot 1)$ but less fat (36.4 (SEm 14.7) \%, $P=0.004$, small effect size $d=0 \cdot 3$ ) during the active video gaming bout than during seated video gaming (carbohydrate $49 \cdot 3$ (SEM 12) \%; protein $6 \cdot 2$ (SEM $2.9) \%$; fat 44.5 (SEM 11.3)\%), as illustrated in Fig. 2. No significant difference was found in the average time to eating onset (min), and similar amounts of the test meal were consumed for which there was no significant difference in ingestion time (min).

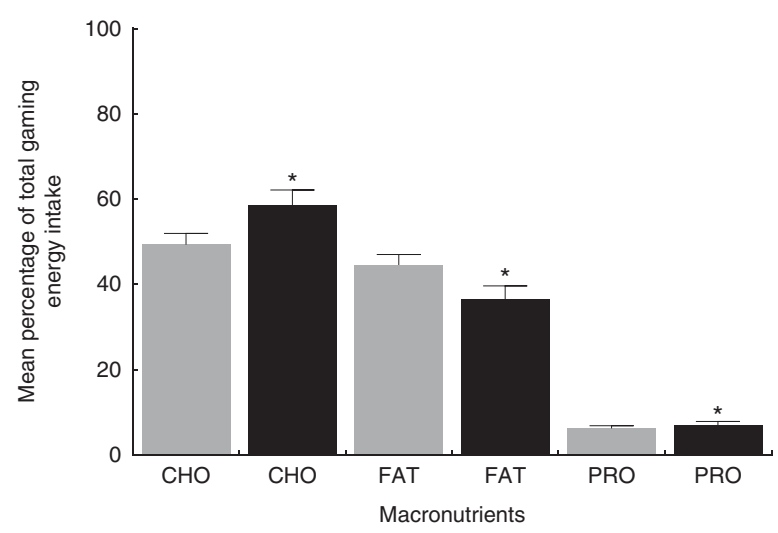

Fig. 2. Mean percentage (\%) macronutrients ingested during gaming for all boys $(n 21)$ as a percentage of total energy intake. *Boys consumed significantly more carbohydrate $(\mathrm{CHO})(P=0.004)$ and protein $(\mathrm{PRO})(P=0.022)$ but significantly less fat $(P=0.004)$ during active video gaming than during seated video gaming.

$\square$, Active gaming; $\square$, seated gaming

As shown in Table 2, following both the active and seated video gaming bouts, the boys were in a positive REI state. REI was significantly greater because of seated video gaming than active video gaming ( $P=0 \cdot 000$, small effect size $d=0 \cdot 4)$. When accounting for the test meal, REI was significantly greater at the end of the seated video gaming compared with active video gaming ( $P=0 \cdot 000$, moderate effect size $d=0 \cdot 6)$.

\section{Plasma glucagon-like peptide-1 and blood glucose}

No significant differences were detected in baseline plasma GLP-1 $_{7-36}(P=0 \cdot 199)$ or blood glucose $(P=0.676)$ between active and seated video gaming. There were no significant 
(a)

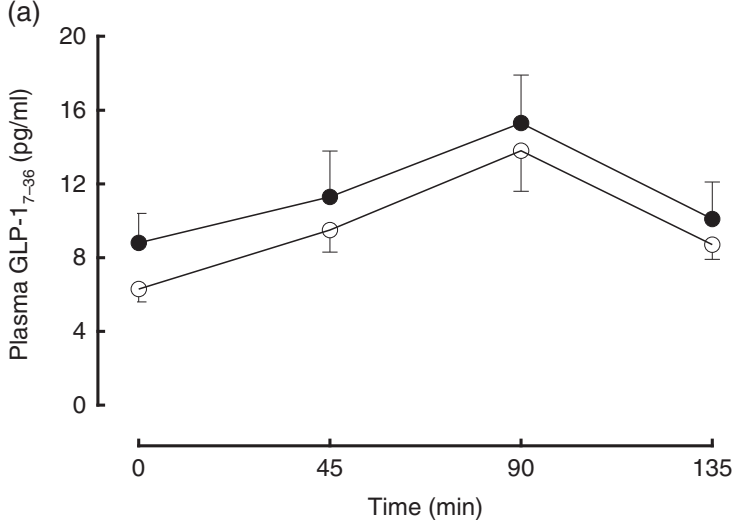

(b)

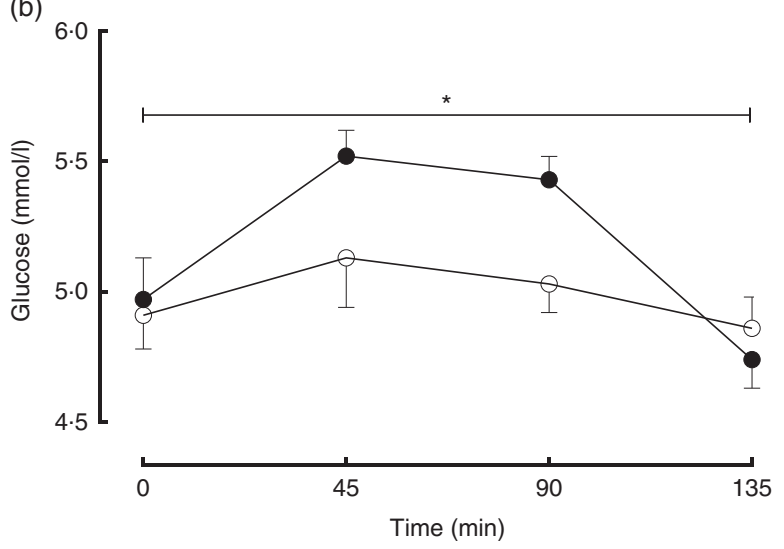

Fig. 3. Time-averaged AUC $\times 135 \mathrm{~min}$ for (a) plasma GLP-17-36 and (b) blood glucose between active and seated video gaming ( $n 20$ boys). (a) No significant differences in plasma GLP-17-36 $(P=0.413)$. (b) * Blood glucose was significantly higher during active video gaming than when seated video gaming $(P=0.037)$. —- Active gaming; $\bigcirc$, seated gaming. GLP-1 ${ }_{7-36}$, glucagon-like peptide-1.

differences in time-averaged AUC $\times 135$ min for plasma GLP- $1_{7-36}$ (Fig. 3(a)) between active and seated video gaming $(P=0.413)$. Time-averaged AUC $\times 135 \mathrm{~min}$ blood glucose was significantly greater during active video gaming $(P=0.037$, small effect, size $d=0 \cdot 3$ ), in comparison with seated video gaming, as illustrated in Fig. 3(b).

\section{Subjective appetite}

There were no significant differences in baseline appetite values for hunger $(P=0.917)$, prospective food consumption $(P=0.204)$ and fullness $(P=0.315)$ between seated and active video gaming. No significant differences were detected in timeaveraged AUC $\times 180 \mathrm{~min}$ for hunger $(P=0 \cdot 884)$, prospective food consumption $(P=0.570)$ or fullness $(P=0.733)$ between the active and seated video gaming trials.

\section{Discussion}

The present study was the first to rigorously explore the satietyrelated signals, plasma GLP-1 $1_{7-36}$ and blood glucose in response to active and seated video gaming in 8-11-year-old boys.
Ad libitum gaming EI and subjective appetite sensations were also measured during $90 \mathrm{~min}$ of gaming and in a post-gaming test meal, to determine whether acute compensation occurred for gaming EI.

The main findings were that the ad libitum gaming EI of 8-11-year-old boys was significantly greater during seated video gaming than during active video gaming. Moreover, EI during both trials was a considerable proportion of daily estimated average requirement (EAR) for energy, for boys aged 9 years, in the UK $(7 \cdot 70 \mathrm{MJ})^{(36)}$. Time-averaged AUC blood glucose was significantly higher during the active video gaming trial ( $t=0-135 \mathrm{~min})$. Examination of the macronutrients revealed that during the 90-min active video gaming bout, the boys were found to have consumed a greater proportion of carbohydrate during these trials, even though overall EI was more when seated. The substantial EI during $90 \mathrm{~min}$ of both seated and active gaming did not result in less EI in the test meal, $1 \mathrm{~h}$ later. In addition, the active gaming EI of the boys was not offset by the estimated energy expended. Consequently, at the end of both 90-min gaming trials, REI was positive, which then increased following consumption of the post-gaming test meal, although this was significantly higher for seated video gaming. Plasma GLP-1 $1_{7-36}$ was raised during both trials, but it did not differ significantly. Subjective sensations of hunger, prospective food consumption and fullness were also no different between trials. However, the subjective responses appeared to reflect the increase in GLP-1 ${ }_{7-36}$ during 90 min of game play and decrease at cessation of both trials. These latter findings are consistent with those found between seated gaming and resting in male adolescents ${ }^{(14)}$ and between seated video gaming and television viewing in 9-13-year-old boys ${ }^{(36)}$.

In the present study, the total EI of the boys during 90 min of seated video gaming was $2.64 \mathrm{MJ}$, whereas in the active video gaming bout EI was significantly lower (1.63 MJ). Per hour, the values obtained for seated video gaming $(1.75 \mathrm{MJ} / \mathrm{h})$ are identical to those found previously in 8-11-year-old boys $(1.75 \mathrm{MJ} / \mathrm{h})^{(11)}$, although the values were higher than those observed in 8-12-year-old children $(1.57 \mathrm{MJ} / \mathrm{h})^{(37)}$. For active video gaming, EI was less per hour $(1.08 \mathrm{MJ} / \mathrm{h})$ than previously established both in $8-11$-year-old boys $(1.41 \mathrm{MJ} / \mathrm{h})^{(21)}$ and in $8-12$-year-old children $(1.60 \mathrm{MJ} / \mathrm{h})^{(37)}$. Differences in $\mathrm{EI}$ between studies could be because of variations in study methodologies, as the current study was situated in the laboratory as opposed to the after-school setting used in our previous work $^{(21)}$. The more familiar and relaxed setting of the school might have induced greater $\mathrm{EI}^{(21)}$. In addition, Mellecker et al. (2008) used a seated video gaming device attached to a treadmill, instead of a genuine active video gaming console ${ }^{(37)}$. The mode of active video gaming was less realistic, and thus it may have been less stimulating and challenging, and this could have induced greater EI than observed at present. In the present study, however, the lower active video gaming EI may have been because of the movement required for game play, which could have made it more difficult to eat than when playing the seated video game. In addition, the longer delay in time to eating onset during active video gaming, although not significant, may help to explain the lower EI. In our previous work with 8-11-year-old boys, however, a significant delay was 
observed in time to eating onset (min) during active video gaming, yet EI was not significantly lower than when seated ${ }^{(11)}$.

The EI of the boys during 90 min of active video gaming, although significantly less than for seated video gaming, when compared with daily EAR for energy ${ }^{(35)}$ was 34 and $21 \%$, respectively, of requirements. When accounting for the estimated EE during the bouts, the REI at cessation of seated and active video gaming was 2.26 and $0.99 \mathrm{MJ}$, respectively. Allowing for the post-gaming test meal, at the end of both trials, REI increased to $3.34 \mathrm{MJ}$ for seated and $2.06 \mathrm{MJ}$ for active video gaming. Although the boys did not compensate for the extra EI during active video gaming by down-regulating their EI at the test meal, the resultant energy surplus was 1.28 MJ lower than when the boys were seated. Nonetheless, the REI for both active and seated video gaming may be clinically meaningful in relation to weight status, as a reduction of only 0.46-0.69 MJ/d may be all that is required to reduce the energy gap and decrease children's body mass ${ }^{(38)}$

As previously reported with television viewing, it is possible that both seated and active video gaming could have a distractive effect, which can lead to over-consumption of energy without an increase in appetite sensations ${ }^{(39)}$. Such an effect is thought to disrupt the habituation to food cues from the sensory, neuronal and digestive systems ${ }^{(39)}$, and as a consequence satiety signals appear to be ignored, thus causing over-compensation in EI for the energy expended ${ }^{(14,36,40)}$. In relation to active and seated video gaming, this disruption, coupled with an environment in which highly palatable foods are available ad libitum, could have activated the brain's reward centre. As a result, satiety peptides might have been down-regulated, and instead an augmented release of hormones associated with pleasure (dopamine, endocannabinoids and opiates) may have been increased. This response is related to hedonic systems and sustains the drive to eat ${ }^{(21)}$.

The only paediatric study ${ }^{(16)}$ thus far to have investigated compensation because of active video gaming EE also did not establish any difference in EI in a post-gaming meal, when compared with $1 \mathrm{~h}$ of resting and seated video gaming. In contrast to the present study, at the end of the active video gaming trial, the boys were in negative REI, although this was compensated for $24 \mathrm{~h}$ later by an increase in $\mathrm{EI}^{(10)}$. However, food was offered ad libitum in a post-gaming test meal only and not both during and following each trial, as in the present study. From the current study, it is not known whether the boys compensated for the extra EI during both gaming trials at a later time, either by a down-regulation in EI or an increase in EE. If no compensation occurred, the REI established for both seated and active video gaming could contribute to a positive energy balance state, and if it is a frequent behaviour it could lead to obesity and thus pose a risk to child health. Further research should consider the effects of active video gaming on subjective and objective appetite over a longer time period, to establish whether compensation for the extra EI occurs more than $1 \mathrm{~h}$ later in 8-11-year-old boys.

The higher time-averaged AUC concentrations of blood glucose and lower EI of the boys during active video gaming most likely occurred from the greater proportion of carbohydrate consumed or the greater EE. However, greater concentrations of blood glucose are also in accordance with the 'glucostatic theory'. The responses of glucose and GLP-1 ${ }_{7-36}$, which increased over the course of the $90 \mathrm{~min}$ of active gaming, may have enhanced satiety and caused this lower EI. Nonetheless, during both active and seated video gaming EI was substantial, and thus a hedonic response should not be dismissed as this may have superseded the homoeostatic signal of GLP-1 ${ }_{7-36}$ to stop eating, during active video gaming $^{(22,41)}$. Future active gaming studies should therefore consider the measurement of insulin and hedonic food intake by VAS.

To the authors' knowledge, the present study initiated the investigation of the acute effects of active and seated video gaming on glucose and GLP-17-36, in 8-11-year-old boys. In addition, fingertip capillary blood sampling was used to quantify GLP-1 1 -36, as this was only recently established as a comparable option to the antecubital-venous method ${ }^{(32)}$. Considering the age of the present study population (8-11 years), this alternative blood sampling technique provided a more suitable method for the collection of blood and thus assessment of GLP-1 $1_{7-36}$ and glucose.

The measurement of hormonal appetite during active video gaming in children is not without limitations. Because of the short half-life of GLP-1 ${ }_{7-36}$, to ensure its preservation, the study was conducted in the laboratory rather than in a school setting, as in our previous work ${ }^{(11,42)}$. The levels of glucose, which were significantly greater during active video gaming than when the boys were seated, might also have stemmed from the low-intensity exercise. As such, further research could include the measurement of lactate to assess the demands of active video gaming ${ }^{(43)}$. The present sample was limited to the study of boys only, because of the physiological aspects primarily related to the different growth and maturation rates to girls during 8-11 years ${ }^{(44)}$. For this reason, the authors believed it inappropriate to include girls, as to do this would have meant subdividing by sex and thus reducing methodological rigour. Future paediatric active video gaming research in relation to EI and appetite would therefore benefit from work with girls.

To conclude, $90 \mathrm{~min}$ of active video gaming decreased EI, yet similar to seated gaming REI was positive following $90 \mathrm{~min}$ of active video gaming, and this was not compensated for in the post-gaming test meal. Instead, the lack of compensation in the post-gaming test meal resulted in an increase in REI, which, although reduced by $1.28 \mathrm{MJ}$ because of active video gaming, is a clinically meaningful amount in terms of body mass ${ }^{(38)}$. Active video gaming and food and drink consumption should not therefore be simultaneous behaviours in children, as this type of eating behaviour could counteract the health benefits of the higher EE, which may then lead to an increase in body mass.

\section{Acknowledgements}

The authors thank all of the schools, the children and their parents who participated in this study. The authors are grateful to Meghan Brown and Liam Harper who assisted with data collection.

The project received no external funding. 
S. A. and P. L. S. R. designed the study; S. A. led and carried out the data collection; B. P. G. assisted with data collection; and S. A., B. P. G., C. J. D.-R., G. B. and P. L. S. R. contributed to data analysis, interpretation and writing of the manuscript.

The authors declare that there are no conflicts of interest.

\section{References}

1. Niblett P (2015) Statistics on Obesity, Physical Activity and Diet: England 2015. London: Health and Social Care Information Centre. Part of the Government Statistical Service.

2. Hughes AR, Sherriff A, Lawlor DA, et al. (2011) Incidence of obesity during childhood and adolescence in a large contemporary cohort. Prev Med 52, 300-304.

3. Almond L, Biddle S, Bull F, et al. (2011) Start Active, Stay Active. A Report on Physical Activity for Health from the Four Home Countries'. London: Crown Copyright.

4. Scholes S \& Mindell J (2012) Physical activity in children. In Health Survey for England [R Craig and J Mindell, editors]. London: The Health and Social Care Information Centre.

5. Huang WY, Wong SH \& Salmon J (2013) Correlates of physical activity and screen-based behaviors in Chinese children. J Sci Med Sport 16, 509-514.

6. Nintendo ${ }^{\odot}$ (2015) Nintendo history. https://www.nintendo.co. uk/Corporate/Nintendo-History/Nintendo-History-625945.html (accessed May 2015).

7. White K, Schofield G \& Kilding AE (2011) Energy expended by boys playing active video games. J Sci Med Sport 14, 130-134.

8. Graf DL, Pratt LV, Hester CN, et al. (2009) Playing active video games increases energy expenditure in children. Pediatrics 124, 534-541.

9. Lanningham-Foster L, Jensen TB, Foster RC, et al. (2006) Energy expenditure of sedentary screen time compared with active screen time for children. Pediatrics 118, E1831-E1835.

10. Maddison R, Mhurchu CN, Jull A, et al. (2007) Energy expended playing video console games: an opportunity to increase children's physical activity? Pediatr Exerc Sci 19, 334-343.

11. Allsop S, Dodd-Reynolds CJ, Green BP, et al. (2015) Acute effects of active gaming on ad libitum energy intake and appetite sensations of 8-11-year-old boys. Br J Nutr 114, 2148-2155.

12. Graves L, Stratton G, Ridgers ND, et al. (2008) Energy expenditure in adolescents playing new generation computer games. Br J Sports Med 42, 592-594.

13. Lam JWK, Sit CHP \& McManus AM (2011) Play pattern of seated video game and active 'Exergame' alternatives. J Exerc Sci Fit 9, 24-30.

14. Chaput JP, Visby T, Nyby S, et al. (2011) Video game playing increases food intake in adolescents: a randomized crossover study. Am J Clin Nutr 93, 1196-1203.

15. Marsh S, Ni Mhurchu C, Jiang Y, et al. (2014) Comparative effects of TV watching, recreational computer use, and sedentary video game play on spontaneous energy intake in male children. A randomised crossover trial. Appetite 77, 13-18.

16. Gribbon A, McNeil J, Jay O, et al. (2015) Active video games and energy balance in male adolescents: a randomized crossover trial. Am J Clin Nutr 101, 1126-1134.

17. Chaput JP, Schwartz C, Boirie Y, et al. (2015) Energy intake adaptations to acute isoenergetic active video games and exercise are similar in obese adolescents. Eur J Clin Nutr 69 , $1267-1271$.

18. Allsop S, Rumbold PLS, Debuse D, et al. (2013) Real life active gaming practices of 7-11-year-old children. Games Health J 2, 347-353.
19. Simons M, Chinapaw M, Brug J, et al. (2015) Associations between active video gaming and other energy-balance related behaviours in adolescents: a 24-hour recall diary study. Int J Behav Nutr Phys Act 12, 32.

20. Mayer J (1952) The glucostatic theory of regulation of food intake and the problem of obesity. Bull New Engl Med Cent 14, 43-49.

21. Finlayson G, King N \& Blundell J (2008) The role of implicit wanting in relation to explicit liking and wanting for food: implications for appetite control. Appetite 50, 120-127.

22. Yeomans MR (1998) Taste, palatability and the control of appetite. Proc Nutr Soc 57, 609-615.

23. World Medical Association (2013) Declaration of Helsinki: ethical principles for medical research involving human subjects. JAMA 310, 2191-2194.

24. van Strien T \& Oosterveld P (2008) The children's DEBQ for assessment of restrained, emotional, and external eating in 7- to 12-year-old children. Int J Eat Disord 41, 72-81.

25. McCarthy HD, Jarrett KV \& Crawley HF (2001) The development of waist circumference percentiles in British children aged 5.0-16.9 y. Eur J Clin Nutr 55, 902-907.

26. Rumbold PLS, St Clair Gibson A, Stevenson EJ, et al. (2013) Influence of netball-based exercise on energy intake, subjective appetite and plasma acylated ghrelin in adolescent girls. Appl Physiol Nutr Metab 38, 1-8.

27. Reilly JJ, Penpraze V, Hislop J, et al. (2008) Objective measurement of physical activity and sedentary behaviour: review with new data. Arch Dis Child 93, 614-619.

28. Evenson KR, Catellier DJ, Gill K, et al. (2008) Calibration of two objective measures of physical activity for children. J Sports Sci 24, 1557-1565.

29. Trost SG, Loprinzi PD, Moore R, et al. (2010) Comparison of accelerometer cut points for predicting activity intensity in youth. Methodol Adv 11, 1360-1368.

30. Henry C (2005) Basal metabolic rate studies in humans: measurement and development of new equations. Public Health Nutr 8, 1133-1152.

31. Ridley K, Ainsworth BE \& Olds TS (2008) Development of a compendium of energy expenditures for youth. Int J Behav Nutr Phys Act 5, 45.

32. Green BP, Gonzalez JT, Thomas K, et al. (2014) Agreement between fingertip-capillary and antecubital-venous appetiterelated peptides. Endocr Connect 3, 233-242.

33. Cohen J (1992) A power primer. Psychol Bull 112, 155-159.

34. Cole TJ, Freeman JV \& Preece MA (1995) Body mass index reference curves for the UK, 1990. Arch Dis Child 73, 25-29.

35. Jackson A (2011) Dietary Recommendations for Energy. Scientific Advisory Committe on Nutrition 2010. London: Scientific Advisory Committee on Nutrition.

36. Marsh S, Ni Mhurchu C \& Maddison R (2013) The nonadvertising effects of screen-based sedentary activities on acute eating behaviours in children, adolescents, and young adults. A systematic review. Appetite 71, 259-273.

37. Mellecker RR, Lanningham-Foster L, Levine JA, et al. (2010) Energy intake during activity enhanced video game play. Appetite 55, 343-347.

38. Wang YC, Gortmaker SL, Sobol AM, et al. (2006) Estimating the energy gap among US children: a counterfactual approach. Pediatrics 118, e1721-e1733.

39. Temple JL, Giacomelli AM, Kent KM, et al. (2007) Television watching increases motivated responding for food and energy intake in children. Am J Clin Nutr 85, 355-361.

40. Dallman MF (2010) Stress-induced obesity and the emotional nervous system. Trends Endocrinol Metab 21, 159-165. 
41. Blundell JE \& Finlayson G (2004) Is susceptibility to weight gain characterized by homeostatic or hedonic risk factors for overconsumption? Physiol Behav 82, 21-25.

42. Rumbold PLS, Dodd-Reynolds CJ \& Stevenson EJ (2013) Informing primary school nutritional policy: effects of mid-morning snacks on appetite and energy control. Food Nutr Sci 4, 529-537.
43. Tolfrey K \& Armstrong N (1995) Child-adult differences in whole blood lactate responses to incremental treadmill exercise. Br J Sports Med 29, 196-199.

44. Armstrong N (editor) (2007) Paediatric Exercise Physiology, Advances in Sport and Exercise Science Series. Edinburgh: Churchill Livingstone Elsevier. 